\title{
NILAI-NILAI PENDIDIKAN KARAKTER DALAM NOVEL SANG PENCURI WARNA KARYA YERSITA (PENDEKATAN PRAGMATIK RESEPTIF)
}

\author{
Paqih \\ SDN Dateng Kecamatan Laren Kabupaten Lamongan \\ HP082257411475; pos-el paqih_karmijo@ymail.com
}

\begin{abstract}
Abstrak: Tujuan penelitian ini adalah mendeskripsikan (1) nilai-nilai pendidikan sosial, (2) nilai-nilai pendidikan agama,dan (3) nilai-nilai pendidikan budaya dalam novel Sang Pencuri Warna Karena Allah Lebih Mencintainya karya Yersita.Rancangan penelitian ini menggunakan metode deskriptif kualitatif dengan pendekatan Pragmatik Reseptif.Metode kualitatif memberikan perhatian terhadap data alamiah, data dalam hubungannya dengan konteks keberadaannya.Hasil penelitian menunjukkanbahwa nilai-nilai pendidikan sosialmeliputi pendidikan karakter: guru sebagai inspirator, memahami karakter anak, nilai karakter bangsa, pendidikan sangat penting. Nilai-nilai pendidikan agama meliputi berdoa, shalat, saling memaafkan, jangan saling menyalahkan, silaturahim, pemberian nama dan ihlash. Nilai-nilai pendidikan budaya meliputi budaya melamar, budaya korupsi, budaya mengancam, dan budaya demonstrasi.Beberapa budaya yang dilakukan oleh tokoh-tokoh dalam novel adalah cerminan dari kehidupan sehari-hari.
\end{abstract}

Kata kunci: pendidikan, karakter, pragmatik, reseptif

Abstract: The purpose of this study is to describe (1) the values of social education, (2) the values of religious education, and (3) the values of cultural education in the novel The Thief of Color Because Allah Loves Yersita's works. The design of this study used a qualitative descriptive method with the Receptive Pragmatic approach. Qualitative methods pay attention to natural data, data in relation to the context of its existence. The results of the study show that the values of social education include character education: teachers as inspirators, understanding children's character, values of national character, education are very important. The values of religious education include prayer, prayer, forgiveness, do not blame each other, friendship, giving names and ihlash. Cultural education values include applying culture, corruption culture, threatening culture, and demonstration culture. Some of the cultures performed by the characters in the novel are a reflection of everyday life.

Keywords: education, character, pragmatics, receptive

\section{PENDAHULUAN}

Perkembangan novel di Indonesia berkembang cukup pesat, terbukti dengan hadirnya berbagai macam novel yang telah diterbitkan, sehingga bentuk dan isi novel tersebut beragam.
Pada dasarnya, novel selalu hadir sebagai sebuah gambaran atau cerminan kehidupan manusia dalam mengarungi kehidupannya. Novel juga merupakan gambaran lingkungan masyarakat yang hidup di suatu masa dan suatu tempat. 
Tokoh dan peristiwa yang disajikan dalam novel merupakan pantulan realitas yang ditampilkan oleh pengarang dari suatu keadaan tertentu.

Sebuah karya satra, termasuk novel biasanya menggambarkan kehidupan pada saat karya sastra itu ditulis. Karya sastra seperti novel selalu menghadirkan berbagai macam nilai-nilai kehidupan dan nilai-nilai pendidikan seperti nilai moral, sosial, budaya, dan religi yang patut untuk diteladani. Oleh karena itu, novel sebagai karya sastra merupakan salah satu jenis dari bacaan masyarakat, turut memberikan pengaruh besar terhadap pembentukan pola pikir masyarakat pembacanya. Novel sebagai salah satu media alternatif bacaan pun harus mampu memberikan hal-hal positif yang ada di dalamnya. Dengan begitu, pembaca pun diharapkan mampu mengaplikasikan nilai-nilai yang ada dalam novel dengan kehidupan sehari-hari.

Novel jika diamati atau diteliti denganperkembangan keadaan dunia, tampak adanya gejala-gejala yang menunjukkan gambaran atau fenomena rendahnya kualitas moral masyarakat. Hal tersebut dapat dicontohkan dari moral seorang anak terhadap orang tua seperti melawan dan menentang mereka, maraknya perilaku seks, mewabahnya penyalahgunaan obat-obatan terlarang, dan lain sebagainya.

Pemaparan di atas, diharapkan dengan adanya pembelajaran sastra di sekolah turut berpengaruh dalam pembentukan watak siswa. Dengan kata lain, tiap kegiatan menyiratkan upaya pendidikan yang bertujuan membina watak siswa. Begitu juga dengan pengajaran sastra, diharapkan mampu menghasilkan manusia-manusia yang berpotensi dan mampu menjadi pribadi yang baik.

Hal inilah yang membuat penulis ingin menjabarkan nilai-nilai pendidikan berupa nilai moral yang ada dalam cerita, dan nilai moral tersebut akan dikaitkan dengan keadaan asli dalam latar cerita, baik yang berkaitan dengan adat, budaya, dan lain sebagainya. Nilai-nilai moral novelSang Pencuri Warna karya Yersita ini bernafaskan persahabatan dan pendidikan di Indonesia. Cerita dalam novel ini menegaskan bahwa keadaan ekonomi bukanlah menjadi hambatan seseorang dalam meraih citacitanya.Kemiskinan merupakan penyakit sosial yang berada dalam ruang lingkup materi. Tokoh-tokoh yang ada dalam cerita selalu menjaga nilai moral dalam kehidupan.

Lahirnya novel ini sangat membantu masyarakat dan pendidikan di Indonesia. Karena penulis sendiri bergelut di dunia pendidikan. Sehingga apa yang diketahui dari seluk beluk dunia pendidikan ia tuangkan dalam karyakaryanya. Termasuk novel yang berjudul Sang Pencuri Warna karena Allah Lebih Mencintainya.

Yersita, lahir di Pangkalpinang, 18 Maret 1982. Ibu dari anak ini memiliki hobi membacam menulis dan travelling. Beberapa karyanya yang berupa cerpen dimuat di beberapa media Bangka. Salah satunya adalah Bangka Pos. Beberapa karya Yersita adalah Inspiring Teacher (2012), Kunci Negara Cermin (2014), dan Peran Guru dalam Pendidikan Karakter (Bunga Rampai artikel Guru) diterbitkan Kantor Bahasa Provinsi Kepulauan Bangka Belitung tahun 2015. Saat ini, ia berprofesi sebagai guru SMAN 1 Merawang, Bangka.

Pemilihan Novel Sang Pencuri Warna karena Allah Lebih Mencintainya karya Yersita sebagai objek penelitian dilandasi oleh beberapa alasan yaitu dari segi ekspresi (surfacestructure) maupun segi kekayaan maknanya (deep stucture). Artinya, novel Sang Pencuri Warna karena Allah Lebih Mencintainya 
memenuhi dua kriteria, yaitu (1) relevansi nilai-nilai eksistensi manusia yang terdeskripsikan melalui jalan seni, melalui imajinasi dan rekaan yang keseluruhannya memiliki kesatuan yang utuh, selaras serta memiliki kepaduan dalam pencapaian tujuan tertentu (integrity, harmony, danunity), dan (2) daya ungkap, keluasan, dan daya pukau yang disajikan lewat bentuk (texture) serta penataan unsur-unsur kebahasaan dan struktur verbalnya (Hugh dalam Al Ma'ruf, 2010: 5).

Alasan diangkatnya aspek kepribadian dalam novel Sang Pencuri Warna karena Allah Lebih Mencintainya sebagai bahan kajian karena novel ini mempunyai beberapa kelebihan. Pokok permasalahan dalam penelitian ini adalah aspek kepribadian tokoh utama yaitu Narayana yang mempunyai kepribadian yang kuat dalam menghadapi berbagai cobaan dalam kehidupannya. Di tempat kerjanya, suaminya, dan semua temanteman yang berada dalam lingkungan sehari-hari.

\section{METODE PENELITIAN}

Rancangan penelitian ini menggunakan metode deskriptif kualitatif dengan pendekatan Pragmatik Reseptif. Penelitian kualitatif adalah prosedur penelitian yang menghasilkan data deskriptif berupa kata-kata tertulis atau lisan dari orang-orang dan perilaku yang diamati (Bogdan dan Taylor dalam Moleong, 1990: 31).

Penelitian ini menggunakan teknik pengumpulan data berupa teknik pustaka, simak, dan catat sesuai dengan penjelasan Sudaryanto (dalam Mahsun, 2005: 90). Analisis data dilakukan dengan teknik analisis kualitatif.

\section{HASIL DAN PEMBAHASAN Nilai Pendidikan Sosial}

Nilai pendidikan sosial yang ditemukan dalam novel Sang Pencuri Warna karena Allah Lebih Mencintainya karya Yersita di antaranya adalah pendidikan karakter, guru sebagai inspirator, memahami karakter anak, nilai karakter bangsa, dan pendidikan sangat penting. Pendidikan karakter adalah suatu sistem penanaman nilai-nilai karakter kepada siswa sekolah yang meliputi komponen pengetahuan, kesadaran atau kemauan, dan tindakan. Untuk melaksanakan nilai-nilai tersebut, baik terhadap Tuhan Yang Maha Esa, diri sendiri, dan sesama. Untuk itu proses pendidikan karakter di sekolah melibatkan semua komponen seperti isi kurikulum, proses pembelajaran dan penilaian, kualitas hubungan, penanganan atau pengelolaan mata pelajaran, pengelolaan sekolah, pelaksanaan aktivitas atau kegiatan ekstrakurikuler, pemberdayaan sarana prasarana, pembiayaan, dan kerja seluruh warga dan lingkungan sekolah.

Guru menanamkan karakter anak dengan memberikan inspirasi untuk selalu mengejar cita-cita. Pada saat mereka sudah bisa meraihnya, tentu saja akan diingat pesan yang diberikan oleh guru. Seperti kutipan berikut :

Aku sangat heran. Sudah empat tahun kepergian Musa, sepanjang tahun itu juga, silih berganti siswa mencari Musa. Mereka yang tidak tahu Musa meninggal, begitu terpukul dengan kepergian Musa yang mendadak. Baru kali ini aku melihat guru yang segitu disayangi siswasiswanya. (Yersita, 2016:13)

Peran guru sangat penting. Guru di era global adalah guru yang mempunyai tugas memberikan pendidikan bermutu secara profesional. Sebagai tenaga pendidikan, guru professional tidak lepas 
dari pencitraan yang diberikan dari orang lain.

Ketidaktahuan seorang guru kerap kali menimbulkan pola asuh yang salah kaprah dalam menangani perilaku anak. Dibutuhkan wawasan yang luas dan pengertian dari guru untuk bisa memahami karakteristik anak hingga perlakuan dan pola asuh yang diterapkan guru pun tepat dan tidak menimbulkan trauma psikologis pada anak.

Ketika guru tidak mengetahi karakter siswa, juga tidak mengetahui keadaan siswa di rumah, pada saat mengerjakan tugas guru tidak akan tahu bagaimana kondisi sosio siswa di rumah. Akhirnya guru hanya akan menyalahkan anak. Seperti kutipan teks berikut :

"Di kertas ulangannya, Berri hanya menuliskan tanda tanya besar. Tidak mungkin dia tidak tahu nama ayahnya," ucap perempuan itu berapi-api.

"Berri tidak punya ayah. Jadi, dia tidak pernah tahu siapa nama ayahnya." (Yersita, 2016:11)

Pada era modern, karakter bangsa sudah mulai lemah. Bangsa ini sudah tidak lagi ada nilai karakter bangsa yang diunggulkan. Semua seakan hilang karena tindakan para pejabat atau petinggi negara. Para atasan dengan seenaknya membuat aturan yang sesuai dengan keinginannya. Bahkan hukum yang yang menjadi aturan negara sudah bisa dibeli seperti kutipan berikut :

Pikiran Musa menerawang jauh, mencerna setiap perkataan emaknya. Setelah merenung dan mencermati setiap kata yang keluar dari mulut perempuan tua itu, Musa sadar, tidak ada yang keliru. Di zaman sekarang, uang yang menjadi panglima. Bahkan, dengan uang, orang bisa membeli hukum di negara ini. Seorang koruptor hanya dihukum dalam hitungan bulan. Hotel prodeo yang menjadi tempat paling menakutkan bagi sebagian orang, disulap menjadi hotel dengan fasilitas yang lengkap. Para koruptor tersebut bisa menghitung secara matematis, berapa uang yang harus dikorupsi olehnya dan hukuman yang akan ia terima. (Yersita, 2016: 17-18)

\section{Nilai Pendidikan Agama}

Nilai pendidikan agama yang ditemukan dalam novel Sang Pencuri Warna karena Allah Lebih Mencintainya karya Yersita di antaranya adalah berdoa, shalat, saling memaafkan, tidak saling menyalahkan, silaturrahim, pemberian nama, dan ikhlas.

Doa memberikan kekuatan pada jiwa manusia di samping setiap usaha yang dilakukannya, selama di jalan yang benar. Setiap usaha manusia diiringi dengan doa yang ditujukan untuk memohon kemurahan dan keselamatan dari Tuhan. Nilai pendidikan karakter berdoa tampak dalam data-data berikut:

"Berpedoman pada al-Qur'an. Ada beberapa makna hidup dalam al-Qur'an. Pertama hidup adalah ibadah. Keberadaan kita di dunia ini tiada lain hanya untuk beribadah kepada Allah Swt. Kedua, hidup adalah ujian, maka kita tidak ada cara lain menyelesaikan hidup kita yaitu hidup dengan penuh kesabaran. Ketiga, kehidupan akhirat lebih baik, sehingga kita harus lebih memprioritaskan kehidupan akhirat dan kehidupan dunia dijadikan bekal menuju akhirat. Dan kehidupan yang keempat, kehidupan itu hanya sementara. Jika kita sadar kehidupan ini sementara, maka berlomba-lombalah dalam kebaikan,". (Yersita, 2016:77-78)

Pada hakikatnya doa itu sangat penting. Manusia ingin apa saja hendaknya selalu membaca doa. Bahkan disarankan setiap waktu dan setiap tindakan apa saja manusia harus berdoa. Karena doa mempunyai tujuan yang sangat berharga. Pada kutipan berikut Nara sangat mengagumi Musa. Namun ia tetap sadar bahwa tidak mudah sekadar berharap. Nara harus memberikan beberapa sikap yang menunjukkan ia 
kagum. Nara juga kerap kali memberikan tindakan bagus dengan harapan supaya Musa perhatian kemudian menerima citanya. Namun, Nara tetap tidak lupa dengan berdoa kepada sang Kholiq. Karena bagaimanapun juga semua urusan takdir, ditentukan oleh Allah Swt. Berikut kutipannya :

Dalam doa aku memohon, Ya Allah, jika Musa adalah jodohku, dekatkan dia padaku. Jika memang Musa terbaik bagi dunia dan akhiratku, permudahkanlah ia bagiku, Namun, jika Musa bukan jodohku, berikanlah keikhlasan padaku untuk menerimanya, dan berikan jodoh yang terbaik untukku. Jika Musa bukan jodohku, jangan engkau siksa aku dengan rasa cinta ini, hilangkanlah perasaan ini, Ya Allah. (Yersita, 2016:88)

Dalam kehidupan sehari-hari, banyak dari kita yang menganggap salat itu hanya sekadar ritual wajib semata. Padahal, Rasulullah SAW telah bersabda bahwa salat itu adalah tiang agama. Hal tersebut menunjukkan bahwa salat merupakan faktor penting bagi berdirinya agama Islam. Dengan demikian, salat juga menjadi faktor yang sangat penting bagi kehidupan kita. Maka, salat dengan segala keutamaannya merupakan suatu kebutuhan bagi kita semua baik kebutuhan individual, keluarga, maupun sosial.

Salat menjadi kebutuhan Musa. Musa tidak pernah meninggallkan salat lima waktu. Musa juga kerap mengerjakan salat sunnah seperti kutipan berikut :

Bulan dan bintang terselubung oleh gelapnya malam, membuat malam semakin pekat. Musa terbangun mendengar lolongan anjing tetangga. Ia ke belakang mengambil wudlu, lalu salat Tahajjud. Setiap malam Musa selalu bermunajat pada Allah Swt. (Yersita, 2016:20)
Musa sangat istiqomah mengerjakan salat sunnah. Salat Tahajud selalu dilaksanakn pada malam hari, ia berharap supaya dirinya dekat dengan Allah Swt. Musa selalu bermunajat, berdoa yang terbaik untuk keluarganya. Dan dengan melaksanakan salat tahajud, Musa berharap segala urusan baik di dunia dan di akhirat selalu berjalan baik. Selain mengerjakan salat Tahajud, Musa juga kerap mengerjakan salat sunnah Dhuha, seperti kutipan data berikut :

Pagi itu, setelah mengobrol dengan guru, kuperhatikan Musa meninggalkan kantor, menuju mushalah. Rutinitas yang selalu dilakukan Musa jia ia tidak mengajar. Ibu Tuti bilang, laki-laki itu selalu salat Dhuha. Kelebihan apa lagi yang ditunjukkan Musa? Seumur hidupku, belum pernah aku melaksanakan shaklat Dhuha. Salat wajib pun sering di akhir waktu. Boro-boro mau melakukan slahat sunnah. Tapi melihat Musa, aku jadi ikut termotivasi. Mulai mencari buku yang mengupas tentang berbagai macam salat sunnah. (Yersita, 2016:54-55)

Hidup di dunia ini seharusnya memang harus saling rukun dan damai. Seperti yang disampaikan oleh sahabat 'Uqbah bin 'Aamir, ia berkata : Aku pernah bertemu Rasulullah SAW, lalu beliau berpesan keapdaku, "Wahai 'Ubah bin 'Aamir, sambunglah orang yang memutuskan hubungan denganmu, berilah orang yang tidak mau memberi kepadamu, dan maafkanlah orang yang berbuat dzalim kepadamu". (HR. Muttafaq 'alaih).

Jika ada masalah hendaknya kita langsung meminta maaf. Seperti yang dilakukan oleh Dodi kepada Beri seperti dalam kutipan berikut :

Dodi menyalami Beri, meminta maaf atas perbuatannya. Beri pun menerima uluran tangan Dodi. (Yersita, 2016:56)

Ketika Dodi melakukan kesalahan, maka Musa memberikan pelajaran 
penting tentang kesalahan. Dan akhirnya Dodi harus meminta maaf kepada Beri. Beripun menerima permohonan maaf dari Dodi. Dalam kutipan lain Ibu Yayuk memohon maaf kepada Musa sebagai berikut :

"Ampuni Ibu, Sa. Maafkan Ibu. Ibu khilaf." Perempuan itu memohon maaf pada Musa. Tangannya memegang baju Musa, lalu ia menunduk, seperti hendak sujud di kaki Musa. Melihat reaksi ibu Yayuk, Musa langsung mengangkat tangan perempuanitu. Tidak membiarkan Ibu Yayuk menyentuh kakinya. "Ibu tidak perlu khawatir. Sebelum Ibu minta maaf, saya sudah memafkan Ibu. Pulanglah ke rumah, jaga Yayuk baik-baik. Maafkan jika saya mengganggu ketentraman keluarga kalian." (Yersita, 2016:57)

Dalam kehidupan bermasyarakat tentu akan ada masalah. Di saat masalah di depan kita. Jangan sampai kita saling menyalahkan. Kita harus saling intropeksi diri. Seperti halnya kutipan berikut :

"Ah, masa bodohlah. Kalian sendiri yang tidak becus mengajar. Sehingga nilainya kecil-kecil semua," ucapnya menyalahkan semua guru yang mengajar pelajaran ujian nasional. (Yersita, 2016:92)

Bersilaturahim itu termasuk amalan mulia yang berpahala besar. Bersilaturahim sangat diserukan untuk umat islam. Karena silaturahim menjalin hubungan antara manusia dengan manusia lain. Salah satu contoh dari silaturahim adalah menjenguk orang sakit, seprti kutipan berikut :

Tapi perubahan besar ditunjukkan oleh Bu Hanna. Ia menyambut siswa-siswa dengan ramah. Siswa semula takut, berubah berani mengungkapkan keinginan mereka. Dan di luar dugaan, Ibu Hanna bersedia menjenguk Andito. Kunjungan ke rumah Andito menjadi kenangan tersendiri. Tubu Andito yang lemah mendadak terasa kuat. (Yersita, 2016:26-27)
Ketika Andito sakit, Musa mengajak semua teman-temannya menjenguk. Bersilaturahim atau menjenguk Andito disamping melihat kondisi kesehatan juga sebagai penyemangat, kemudian mendoakan supaya cepat sehat.

Pemberian nama atau yang sering disebut Walimatus Tasmiyah adalah tanggung jawab orang tua kepada anak. Pemberian nama ini biasanya selalu berhubungan tujuan. Diberi nama Muhammad berharap sifat dan kelakuannya seperti Muhammad. Seperti halnya Musa, orang tua Musa memberi nama Musa dengan harapan menajdi manusia yang tangguh segalanya seperti kutipan berikut :

“Ayah memberimu nama Musa, biar kau tangguh seperti Nabi Musa. Meskipun kelak kehidupan terasa berat bagimu, ingat Allah Swt. Selalu menyertai orangorang yang bertaqwa pada-Nya." (Yersita, 2016:21)

Pada novel Yersita yang berjudul
Sang Pencuri Warna banyak
memberikan beberapa pelajaran kehidupan, di antaranya adalah ikhlas. Keikhlasan Musa sangat jelas seperti kutipan berikut :

Musa Ikhlas, Mak. Musa Ikhlas...," ucapnya pelan.

Dibelainya wajah perempuan itu untuk terakhir kali. Musa kecup kening emaknya, ah, hati Musa terasa remuk. Belum pernah ia merasakan sesakit ini ditinggalkan. Tak ada isyarat apa pun dari kepergian emaknya. Perempuan itu bahkan tidak mengatakan apa pun tentang itu. Dan keyakinan Musa semakin bertambah. Jika sudah sampai pada waktunya, tidak ada seorang pun yang bisa menolong kecuali amal dan perbuatannya. Musa yakin jika emaknya meninggal dalam keadaan khusnul khatimah. Dalam hati, Musa memohon agar emak ditempatkan di janah-Nya. (Yersita, 2016:117) 


\section{Nilai Pendidikan Budaya}

Lamaran adalah tahapan pertama yang harus dilalui dalam suatu pernikahan yang umumnya dilakukan oleh kaum pria untuk menyampaikan niat dan kesungguhannya untuk menikah serta meminta restu dan persetujuan dari orang tua wanita yang akan dinikahi.

Nara, sangat berharap bisa menikah dengan Musa. Tapi bagaimanapun juga Nara tidak berani semena-mena. Maka berbagai cara dilakukan Nara. Termasuk meminta kepada Ibu Tuti untuk melancarkan hubungannya dengan Musa. Perhatikan data berikut:

Ia takut lamarannya ditolak. Adat mereka mengharuskan seorang laki-laki memberikan hantaran berupa uang untuk mengadakan pesta di rumah mempelai perempuan. (Yersita, 2016:18)

Hari itu aku memegang janji Ibu Tuti yang akan membantu hubungan kami. Ia yakinkan padaku, jika akan menyampaikan pada Musa keinginanku menikah dengannya. Sebelumnya, Ibu Tuti menceritakan bagaimana Siti Khadijah memutuskan untuk melamar Muhammad dengan cara yang terhormat. Ia mengutus sahabatnya yang bernama Nafisah untuk menjadi perantara dalam menyampaikan perasaannya kepada Muhammad. Dan aku katakan pada Ibu Tuti bahwa dia berperan sebagai Nafisah dalam menyampaikan amanah pada Musa. (Yersita, 2016:179)

"Iya Musa datang untuk melamar Nara. Tapi ini baru pembicaraannya pada papa. Pembicaraan yang lebih serius, dia masih menunggu keputusan dari papa. Menolak atau menerima lamarannya. Jika diterima, Musa bilang akan datang lagi bersama pamannya." (Yersita, 2016:193)

Musa didatangi $\mathrm{Bu}$ Siti, menanyakan sekaligus melantarkan hubungannya dengan Nara. Disaat yang berbeda Musa diberitahu sekaligus diminta oleh Ibu Siti untuk segera ta'aruf ke rumah Nara. Ta'aruf adalah kegiatan berkunjung ke rumah seseorang untuk berkenalan dengan penghuninya. Ta'aruf dapat menjadi langkah awal untuk mengenalkan dua keluarga yang akan menjodohkan salah satu anggota keluarga. Ini adalah tahapan pertama yang dilakukan oleh Musa kepada keluarga Nara.

Setelah tahapan ta'ruf selesai. Kedua keluarga sudah sama-sama suka, jenjang berikutnya adalah penentuan hari pernikahan. Dengan fasih dan kesiapan Musa menikahi Nara seperti kutipan berikut :

"Saya nikahkan dan saya kawinkan anak saya yang bernama Narayana Binti Haris Gunawan dengan maskawinnya berupa seperangkat alat sholat, tunai." (Yersita, 2016:203)

Musa meraih kesempurnaan dalam hidupnya, setelah ia menikahi Nara. Musa dan Nara menemukan kehidupan baru. Ia benar-benar bahagia. Pernikahan adalah upacara pengikatan janji nikah yang dirayakan atau dilaksanakan oleh dua orang dengan maksud meresmikan ikatan perkawinan secara norma agama, norma hukum, dan norma sosial. Upacara pernikahan memiliki banyak ragam dan variasi menurut tradisi suku bangsa, agama, budaya, maupun kelas sosial.

Korupsi adalah tindakan seseorang yang menyalahgunakan kepercayaan dalam suatu masalah atau organisasi untuk mendapatkan keuntungan. Tindakan korupsi ini terjadi karena beberapa faktor faktor yang terjadi di dalam kalangan masyarakat, pendidikan, organisasi, instansi dan lain sebagainya.

Dalam dunia pendidikan banyak terjadi korupsi. Misalnya korupsi waktu atau korupsi mengerjakan soal. Seperti kutipan berikut :

"Jadi kami memutuskan agar semua guru mata pelajaran ujian nasional membantu mencari jawaban. Nanti kami 
persiapakan ruangan tersendiri, jawaban akan kita edarkan di empat sekolah kecamatan kita. Tidak perlu takut dengan pengawas independen, karena kita kondisikan." (Yersita, 2016:102)

"Mengapa moralitas masyarkat Indonesia sangat rendah? Mengapa pula tingkat kriminalitas di negara ini tinggi, dan kita menjadi negara terkorup nomor tiga di dunia? Bukankah semuanya bermuara pada sistem pendidikan?" (Yersita, 2016:131)

Data di atas menunjukkan bahwa semua guru se kecamatan berbondongbondong untuk kerja sama membantu mengerjakan soal ujian nasional susulan. Hal itu dilakukan karena pada saat ujian nasional pertama, hampir $80 \%$ anak-anak tidak lulus. Melihat realita tersebut, tidak ada jalan lain kecuali melakukan korupsi bersama-sama dalam hal membantu mengerjakan soal. Namun Nara menolak dengan tegas, ketika ada konspirasi besar terkait dengan pengerjaan soal.

Pada kutipan data tersebut salah seorang guru menunjukkan keadaan di Indonesia. Betapa banyaknya moralitas anak dan berapa banyak para pejabat negara korupsi. Semua itu terjadi karena sistem pendidikan kita. Apalagi pada saat situasi yang sulit harus menunjukkan jawaban kepada anak-anak. Selama mereka sekolah di sana tiga tahun, dan hanya dalam empat hari pelaksanaan ujian nasional semuanya dihancurkan. Inilah dampak dari korupsi dalam konspirasi mengerjakan ujian nasional.

Tidak jauh berbeda dengan kehidupan bermasyarakat atau di dunia pendidikan, juga kerap ada sebagian kecil mengancam. Yersita memberikan ulasan mengenai ancaman sebagai berikut :

"Saya sekarang sedang di Dinas Pendidikan, Bu. Jika saya katakan kepada kepala dinas, Ibu bisa dimutasi," ancam Bapak Suratman.
"Saya tidak peduli, Pak. Silahkankatakan saja pada kepala dinas, saya tidak takut." (Yersita, 2016:126)

Ketika Nara tidak mau diajak untuk konspirasi mengerjakan soal. Kepala sekolah bertindak dengan mengancam keberadaan Nara. Rencananya akan dimutasi pada sekolah lain dengan memperjelek kinerja. Namun, Nara tetap tegas dan tegar dengan membalas semua ancaman yang disampaikan oleh kepala sekolah.

Di Inonesia, budaya mengancam masih sering kita dengar. Di lingkungan sehari-hari, atau di lingkungan sekolah. Di sekolah sering dijumpai ketika anak menyuruh temannya tidak mau, maka anak tersebut pasti mengancam. Budaya saling ancam ini semestinya harus segera diselesaikan dengan berbagai cara. Misalnya memberikan ulasan tentang bahaya mengancam dan lain sebagainya.

Dalam lingkungan sekolah Nara, ada ketidakjelasan tentang pemecatan Musa. Musa dinilai karena tidak bisa diajak kerja sama oleh kepala sekolah, Musa juga dikambinghitamkan oleh kepala sekolah terkait dengan kedekatan siswa. Semua dilakukan kepala sekolah untuk menutupi apa yang sudah dilakukan kepala sekolah, seperti kutipan berikut :

"Jangan pecat Bapak Musa jika ingin sekolah tetap berlangsung," ancam seorang siswa lain.

Bapak Suratman! Ayo keluar! Kami ingin bicara dengan Bapak," ucap Wahyu. Diikuti yel-yel yang membuatku dan Ibu Tuti terkikil geli.

Bapak Suratman..., Bapak Suratman...,

Bapak Suratman..., ayo keluar! Bapak

Suratman..., (Yersita, 2016:163)

Demonstrasi sebenarnya bisa dilakukan ketika tahapan-tahapan usaha penyelesaian tidak disetujui. Namun ketika beberapa tahapan itu tidak bisa, maka usaha berikutnya adalah 
demonstrasi. Seperti halnya pada kutipan di atas. Musa yang tidak tahu menahu tentang masalah pembagian jawaban ujian nasional kepada anak, justru malah dikambinghitamkan. Dan dengan entengnya Musa dipecat.

Pemecatan Musa tidak realistis, tidak sesuai dengan keadaan di sekolah. Musa adalah sosok guru yang paling baik di sekolah. Musa paling rajin. Musa paling disayangi murid. Sehingga semua murid merasa ada penyelewengan tindakan dari kepala sekolah. Tentunya langkah yang ditempuh adalah dengan demonstrasi. Pada langkah ini, akhirnya Musa tetap menjadi guru di sekolah tersebut.

\section{SIMPULAN}

Nilai-nilai pendidikan sosial dalam novel Sang Pencuri Warna Karena Allah Lebih Mencintainya karya Yersita meliputi pendidikan karakter, guru sebagai inspirator, memahami karakter anak, nilai karakter bangsa, pendidikan sangat penting. Di dalam pendidikan karakter sangat dibutuhkan contoh terbaik untuk peserta didik. Hal ini karena sedikit hal yang dikerjakan oleh guru, peserta didik akan memerhatikan dan mempraktikkan dalam keseharian.

Adapun nilai-nilai pendidikan agama dalam novel Sang Pencuri Warna Karena Allah Lebih Mencintainya karya Yersita adalah berdoa, shalat, saling memaafkan, jangan saling menyalahkan, silaturahim, pemberian nama, dan ikhlash. Penulis berusaha memberikan ulasan tentang pendidikan karakter agama. Banyak contoh-contoh yang diberikan kepada pembaca melalui tokoh Musa. Dalam keseharian Musa kerap kali memberikan pendidikan karakter dari segi agama seperti yang di ulas pada bab sebelumnya.

Nilai-nilai pendidikan budaya dalam novel Sang Pencuri Warna Karena
Allah Lebih Mencintainya karya Yersita adalah budaya melamar, budaya korupsi, budaya mengancam, dan budaya demonstrasi. Beberapa budaya yang dilakukan oleh tokoh-tokoh dalam novel adalah cerminan dari kehidupan seharihari. Penulis memberikan ulasan deskripsi sedikit mengenai beberapa nilai-nilai pendidikan karakter budaya.

\section{DAFTAR PUSTAKA}

Abidin, Rohman. 2014. Nilai-nilai Akhlaq dalam Kitab Bidayat AlHidayah Al-Ghazali Dan Relevansinya Dengan Pendidikan Karakter Di Indonesia. Surabaya : UINS.

AliahDarma, Yoce. 2007.Analisis Wacana Kritis. Bandung:Yrama Widya.

BurhanNurgiyantoro.2005.TeoriPengkaji anFiksi.Yogyakarta: GajahMada Press.

Damono, Sapardi Djoko. 1979. Sosiologi Sastra: Sebuah Pengantar Ringkas. Jakarta Pusat: Pusat Pembinaan dan Pengembangan Bahasa.

Herman J. Waluyo. 2006. Pengakajian dan Apresiasi Prosa Fiksi. Surakarta: UNS Press.

Mahayana, Maman S. Ekstrinsikalitas Sastra Indonesia. Jakarta: PT RajaGrafindo Persada. 2007

Mahfud. 1997. Pengantar Ilmu-Ilmu Sosial. Jakarta: Sinar harapan.

Minderop, Albertine. Metode Karakterisasi Telaah Fiksi. Jakarta: Yayasan Obor Indonesia 2005

Moleong, Lexy J. Metodologi Penelitian Kualitatif. Bandung: PT Remaja Rosdakarya. 2011

Mutmainnah . 2013. Nilai-nilai Pendidikan karakter dalam novel Sepatu Dahlan karya karya Khrisna Pabichara dan 
implikasinya. Jogjakarta :UIN Sunan Kalijaga.

Natawidjaja, Suparman. Apresiasi Sastra dan Budaya. Jakarta: PT Intermasa. 1982

Pradopo, Rachmat Djoko. 2007. Pengkajian Puisi. Yogyakarata: Gajah madaUniversity Pres.

Praptiwi, Rosita. 2014. Kritik Sosial dalam Surga Retak Karya Syahmedi Dean. Skripsi Pendidikan Bahasa Indonesia Universitas Muhammadiyah Surakarta.

Ridlowi, Ahmad. 2011. Nilai-Nilai Pendidikan Akhlak Dalam Novel Edensor Karya Andrea Hirata Dan Relevansinya Dengan Pendidikan
Islam.Yogyatakarta :UIN Sunan Kalijaga Yogyakarta.

Sangidu. 2004. Penelitian Sastra : Pendekatan, Teori, Metode, dan Kiat. Yogyakarta: UGM Press

Wan. 2016. Tega Hati Brigadir Polisi Mutilasi Dua Anak Sendiri. Jawa Pos, Sabtu, 27 Januari 2016.

Wellek, Rene dan Austin Warren. 2014. Teori Kesusastraan ( terjemahan Melani Budianta). Jakarta :PT Gramedia.

Widowati, Dyah Ayu. 2014. Problematika Pembelajaran Bersastra di SMA Negeri 3 Bantul dengan Pendekatan Pragmatik Reseptif. Yogyakarta: Universitas Negeri Yogyakarta. 